\title{
An Exploration to Edition Identification of Ancient Chinese Maps
}

\author{
Yang Fen \\ Peking University Library, Beijing, China
}

\section{Email address:}

yangf@lib.pku.edu.cn

\section{To cite this article:}

Yang Fen. An Exploration to Edition Identification of Ancient Chinese Maps. International Journal of Information and Communication Sciences. Vol. 3, No. 2, 2018, pp. 26-32. doi: 10.11648/j.ijics.20180302.12

Received: June 5, 2018; Accepted: July 25, 2018; Published: August 18, 2018

\begin{abstract}
Among the Chinese ancient resources collections, map is one remarkable kind of it. How to identify the edition of the maps has become the important work of the collation. Based on the Compilation Program of "Ancient Chinese Maps Collected in Peking University Library", this article analyzes a large number of ancient Chinese maps, and summarizes four valuable methods of map edition identification. First, taboo clues can be taken as the guidance for identifying the edition year of ancient Chinese maps; Second, the toponymic evolution information is obviously an important analysis point in the textual research of editions; Third, edition identification through background investigation, such as background associated with map compilation history or thematic maps, even including divergent associated background investigation; Fourth, relevant important archives could also play a key role in the identification of edition year. In the conclusion, the author emphasizes that comprehensive clues shall be applied in an overall analysis and research for editions of ancient Chinese maps in actual collation work. It also showed that the textual research on maps highlights its own peculiarity while sharing some same features as that of ancient Chinese books. This work requires accumulated practical experience during the actual work, as well as constant learning to increase comprehensive knowledge.
\end{abstract}

Keywords: Maps, Edition, Ancient Chinese, Textual Research, Peking University Library

\section{Introduction}

The collection of ancient Chinese maps in Peking University Library presents a unique stance in the collection of ancient Chinese books. With the same sources of the collected Chinese rare books, the ancient Chinese maps stem from previous collections of Imperial University of Peking and library collections of Yenching University during national colleges \& departments re-arrangement in 1952. Imperial University of Peking mainly collected ancient Chinese maps compiled and published by Chinese people, whereas Yenching University focused on ancient Chinese maps made by foreigners. As a result, the two special sources contribute to the current collection of ancient Chinese maps in Peking University, which covers more than 1000 categories of comprehensive Chinese and foreign-made maps. In September 2014, Peking University Library and Zhonghua Book Company worked together to publish "Collection of Ancient Chinese Maps in Peking University Library", which ushered into a new era of the collation work of collected ancient Chinese maps. The collection was carried out according to the ancient Chinese maps made before 1949, and impressive over 600 categories of maps were included, involving historical and geographical, river and water conservancy, coastal defense and frontier defense, road and mileage, scenic spots and historical sites, and administrative area maps.

This program specially invited Professor Li Xiaocong from Center for Ancient Chinese Classics \& Archives of Peking University as a consultant. Professor Li conducted a professional textual research on the collected ancient Chinese maps with an unclear edition year in the original catalogue. As Professor Li wrote in the book entitled Enlightenment of Ancient Chinese Maps, "Although ancient Chinese maps seem to be less accurate than those in the west, they excel at a clear practicality. No matter for the government or for folks, Chinese maps were made for the purpose of use, rather than simply for private collection. [1]" "Because the traditional Chinese society had a practical requirements for maps, most of ancient Chinese maps lacked names of maker, drawers or 
engravers and the production year [2]." Therefore, it is generally difficult to conduct a textual research on editions of traditional ancient Chinese maps, and make a catalogue for them. By virtue of his academic accomplishments in history, geography and textology, Professor Li solved some difficult problems in the textual research on editions of the collected ancient Chinese maps, gave many professional opinions, including very valuable methods required in identifying editions of ancient Chinese maps and cataloging them. On the basis of Professor Li's practices in identifying the collected ancient Chinese maps, the key points and ideologies of the textual research on editions of ancient Chinese maps have been summarized so as to facilitate the collation work of ancient Chinese maps.

\section{Edition Identification with Taboo Clues}

During the collation work of ancient books, taboo words are often used as the clues for identify ancient books without edition information. Mr. Chen Yuan wrote in Examples of Historical Taboos, "Taboo is a peculiar custom of China... Its abuse could cause the confusion in ancient books, whereas its proper use could help explain doubts in them and identify the authenticity and the age of ancient books. [3]" This method can also be adopted in the textual research on editions of ancient Chinese maps. For this purpose, researchers shall know well about names of Chinese emperors in each dynasty to identify taboo words in maps. Moreover, they shall be familiar with the places involving the names of Chinese ancient emperors so as to quickly lock in the specific geographic position in a map and prove if it is tabooed. Because the existing ancient maps are mainly dated from the Ming and Qing Dynasties, especially from the Qing Dynasty, this method can be taken to quickly initiate the edition analysis and then conclude its approximate age.

Historical Evolution Atlas: From Tribute of Yu to the Ming Dynasty (SB/981.209/3456) is a folded ink-drawing edition containing 32 maps from the Tribute of $\mathrm{Yu}$, the states in the Spring and Autumn Period to the provinces, prefectures, states, counties and garrisons of the Ming Dynasty. The original book cover is inscribed with "Presented by Art Academy of the Ming Dynasty", which is easily mistaken as a book of the Ming Dynasty. Nevertheless, the taboo information can be found to solve this confusion. First of all, Chinese characters “靖卤 (jinglu)” were found in the comprehensive map of provinces, prefectures, states, counties and garrisons of the Ming Dynasty, and "卤 (lu)" was changed from former taboo Chinese character “虏(lu)". In the Qing Dynasty, “虏 (lu)”, “胡 (hu)”, “戎 (rong)”, “蛮 (man)”, “夷狄 (yidi)” were all contemptuous appellations from the Han people to the minorities, and listed as taboos. This clue implied that this atlas was impossibly drawn in the Ming dynasty, but should be made in the Qing Dynasty. Furthermore, other taboo clues of ancient emperor names were also found in many maps. Specifically in the
"Xuanzong 15-Prefecture Map", Chinese character “玄 (xuan)" in the caption lacks the last stroke; Chinese characters “兔玄 (tuxuan)" in the "Map of the North Wei Dynasty", and “弦 (xuan)" in the map of the states in the Spring and Autumn Period, both lack the last stroke to taboo the the name of Emperor Kangxi; Chinese character "真 (zhen)" in the map of the Southern Song Dynasty, remains unchanged, although it is a taboo to the name of Emperor Yongzheng. Considering the above taboo clues, the atlas is identified as a historical evolution maps that was painted during the Kangxi Period of the Qing Dynasty (1662-1722).

Comprehensive Atlas of the Qing Dynasty (SB/981.2/1147) contains eight block-printed thread-bound brochures, including hundreds of maps of 19 provinces of the Qing Dynasty, like Zhili, Shengjing, Jiangnan, Jiangxi and Fujian. However, there is not any edition information in the books. In this case, Professor Li started at the "maps of Zhili", and found the "Eastern Tombs of the Qing Dynasty" in the second map, which only indicates the "Xiaoling Tomb" of Emperor Shunzhi and the "Jingling Tomb" of Emperor Kangxi within the territory of Zunhua. This clue implied that this map might be engraved and printed in the Emperor Yongzheng Period, which could be further proved by any taboo words about the name of Emperor Yongzheng. The first map of Zhili shows “正定 (Zhengding)”, a place name of Hebei Province, which was formerly known as “真定 (Zhending)" before the Yongzhen Period of the Qing Dynasy but changed into “正定 (Zhengding)” for tabooing the name of Emperor Yinzhen in the first year of the Yongzhen Period. In addition, the "maps of Jiangnan" show the "boundary of 仪徵 (Yizheng)", a place name of Jiangsu Province, which was formally known as “仪真 (Yizhen)” and later changed into “仪徵 (Yizheng)” for tabooing the name of Emperor Yinzhen. Therefore, this atlas should be engraved during the Yongzhen Period of the Qing Dynasty (1723-1735).

Map of Unified Territory of the Ming Dynasty (SB/981.2/4611) indicates "a total of one thousand three hundred and thirty-six counties, two hundred and fifty-eight states, and one hundred and eighty-one prefectures within the unified territory of the Ming Dynasty" in the upper left corner. It was originally catalogued as the block-printed edition of the Ming Dynasty. Nevertheless, Chinese character “宁 (ning)" lacks the last stroke throughout the map, such as “西 宁府 (Xining Prefecture)”, “宁夏府 (Ningxia Prefecture)”, “宁武府 (Ningwu Prefecture)”, “江宁府 (Jiangning Prefecture)”, “宁海 (Ninghai)”, “永宁州 (Yongning State)”, “宁州 (Ningzhou State)”. This is for tabooing the name of Emperor Daoguang, and it indicates the upper limit of the edition year of this map. In addition, "Fuhengwan Painting Shop" in a small font was found at the left side. So its overall edition was identified as the block-printed edition engraved by Fuhengwan Painting Shop between the first year of the Daoguang Period and the fourth year of the Xianfeng Period of the Qing Dynasty (1821-1854), and its title was revised into the "Map of Provinces of the Qing Dynasty". Another collection Comprehensive Geographic Atlas of the Qing Dynasty (SB/981.2/3474) is a color-drawing edition of the 
Daoguang Period of the Qing Dynasty (1821-1850). In 21 hand-drawing colored maps, Chinese character “宁 (ning)" is changed into “甯 (ning)”, such as “江甯府 (Jiangning Prefecture)” in the map of Jiangsu, “甯国府 (Ningguo Prefecture)” in the map of Anhui, “武甯 (Wuning)” and “义 甯 (Yining)” in the map of Jiangxi, “建勇府 (Jianning Prefecture)” in the map of Fujian, “永甯 (Yongning)” in the map of Henan, “济甯 (Jining)” and “甯阳 (Ningyang)” in the map of Shandong, “保甯府 (Baoning Prefecture)" and “甯远府 (Ningyuan Prefecture)”in the map of Sichuan, and “甯夏府 (Ningxia Prefecture)”in the map of Gansu. This is another common phenomenon of tabooing the use of Chinese character “宁 (ning)".

As shown in the above examples, taboo clues can be taken as the guidance for identifying the edition year of ancient Chinese maps. However this method requires dialectical study on taboo words to avoid a blind conclusion. As Professor Li Zhizhong said, "The editions of ancient books shall not be identified with only single evidence. Even if the taboo word is defined, other verification methods must also be adopted. The identification result cannot be finally determined until multiple evidences are all considered.[4]"

\section{Edition Identification Through Toponymic Evolution}

In the Overview of Textology of Ancient Chinese Books, Professor Li Zhizhong expounds the edition identification based on toponymic evolution in a special section. The edition identification information could be obtained from the changed place names in the inscriptions and colophon and in the text of ancient Chinese books, and even the names of some small places like palaces and gates. [5] Because Ancient Chinese maps reflect historical and geographical cultures, the toponymic information is obviously an important analysis point in the textual research of editions. Through studied on the background of geographical evolution and changed place names, the map-drawing year could be accurately identified. However, because of China's long history, vast territory and successive dynasties, its historical and geographical evolution is extremely complicated. In this case, the edition identification requires constant accumulation of relevant knowledge and reference to related books. For instance, Comprehensive Table of Evolution of Administrative Areas of the Qing Dynasty compiled by Niu Pinghan. This book states the evolution of local administrative areas of the Qing Dynasty, and indicates the establishment, merger, migration, name change and affiliation of administrative organizations. [6]

Comprehensive Atlas of Imperial Territory the Qing Dynasty (SB/981.2/4327) contains 24 maps in one folded book. It was originally catalogued as the block-printed edition of the Qing Dynasty, with an unclear edition year. Nevertheless, there are several important informations needed to be analyzed. First, the "Comprehensive Map of Zhili" indicates "Wangdu County", which was affiliated to
Baoding Prefecture of Hebei Province and renamed from Qingdu County in the $10^{\text {th }}$ month of the $11^{\text {th }}$ year of the Qianlong Period (November 20, 1747). [7] Therefore, this map may be printed after the $11^{\text {th }}$ year of the Qianlong Period. Secondly, the "Comprehensive Map of Jiangxi" indicates "Ningdu State", which was formerly Ningdu County affiliated to Ganzhou Prefecture and upgraded to a state directly under the provincial government on the $13^{\text {th }}$ day of leap April of the $19^{\text {th }}$ year of the Qianlong Period (June 3, 1754), with two counties in its jurisdiction.[8] In the late Qing Dynasty, Ningdu State directly under the provincial government had two counties in its jurisdiction, namely Ruijin and Shicheng.[9] This also proves the period after the place was upgraded into a state during the Qianlong Period. Thirdly, the "Comprehensive Map of Shaanxi" indicates "Xing'an State" in a small font in the lower right corner; and the "Comprehensive Map of Sichuan" also indicates the "boundary of Xing'an State" in the upper right corner. In early Qing Dynasty, Xing'an State was called Xing'an State directly under the government of Shaanxi Province according to its name of the Ming Dynasty. On the $11^{\text {th }}$ day of the $9^{\text {th }}$ month of the $47^{\text {th }}$ year of the Qianlong Period (October 17, 1782), it was upgraded into a state directly under the provincial government. [10] Because "Xing'an State" is not upgraded into a prefecture in this map, the edition year is inferred to be before the $47^{\text {th }}$ year of the Qianlong Period. Furthermore, two Chinese characters “歷山 (Lishan Mountain)" was noticed at the junction of Yuanqu County, Yicheng County, Yangcheng County and Qinshui County in the south of Shanxi Province in the middle and lower part of the "Comprehensive Map of Shanxi". As Mr. Chen Yuan wrote in the Examples of Taboos, "Emperor Gaozong is named '弘曆 (hongli)', which is substituted with '宏歷 (hongli)'.’[11] Chinese character “歷 (li)” is a taboo Chinese character of the Qianlong Period. Through the mutual verification between the place names and the taboo clues, the atlas is determined to be reproduced based on the Comprehensive Map of Imperial Territory of the Kangxi Period during the Qianlong Period of the Qing Dynasty (1747-1781).

Comprehensive Map of Korea (SB/982.22/4286) is a hard-won scroll of Korean block-printed ink edition, with a total length of $75 \mathrm{~cm}$ and a total width of $209 \mathrm{~cm}$. However, it is difficult to identify the engraving year because of no edition year on the map. Professor $\mathrm{Li}$ pointed out two information points in the map, namely "Changning" and "Ningguta". Changning County was established in Baiduna (today's Fuyu, Jilin Province) in the $12^{\text {th }}$ month of the $4^{\text {th }}$ year of the Yongzheng Period (January 12, 1727) [12] and cancelled on the $5^{\text {th }}$ day of the $7^{\text {th }}$ month of the $1^{\text {st }}$ year of the Qianlong Period (August 11, 1736) [13]. Ningguta Commander-in-Chief was established in the $10^{\text {th }}$ year of the Shunzhi Period (1653), and changed into Ningguta Garrison General in the first year of the Kangxi Period (1662) and Jili Garrison General in the $8^{\text {th }}$ month of the $22^{\text {nd }}$ year of the Qianlong Period (September 20, 1757) [14]. Because there are "Changning" and "Ningguta" in the map, the map is 
identified as a block-printed edition in early Qing Period (1644-1735).

Atlas of Territory of the Qing Dynasty (SB/981.2/1176) is block-printed color ink folded brochure, including 18 maps such as Shengjing, Zhili, Jiangnan, Jiangxi and Zhejiang. Among them, the "Map of Sichuan Province" shows "Suiding Prefecture" in a box. "Suiding" was formerly known as "Dazhou" in early Qing Dynasty, which was the name of the Ming Dynasty and affiliated to "Kuizhou Prefecture". In the $11^{\text {th }}$ month of the $6^{\text {th }}$ year of the Jiaqing Period (December 31, 1801), Dazhou State directly under the provincial government was upgraded into a prefecture and renamed Suiding. [15] This clue of toponymy evolution implies the edition year. Furthermore, Chinese character "宁 (ning)" is not taboo in all of the maps. Therefore, the edition year of this atlas could be limited to the middle and late Jiaqing Period of the Qing Dynasty, namely after the $6^{\text {th }}$ year of the Jiaqing Period but before Daoguang Period (1802-1820).

Atlas of Ji-Liao-Re Border Area (ratio: 1: 500, 000, $\mathrm{X} / 981.2 / 3262$ ) is a color-printed edition compiled by the measurement department, containing five maps of Jinzhou, Chengde, Yongping, Xuanhua and Beijing. To analyze the year of the version, the first clue is that Chaoyang Prefecture directly under the provincial government was upgraded from Chaoyang County in the $4^{\text {th }}$ month of the $29^{\text {th }}$ year of the Guangxu Period (May 6, 1903). This is labeled in the map. The second clue is that Longhua County was established at Tangsanying Town in the $12^{\text {th }}$ month of the $1^{\text {st }}$ year of the Xuantong Period (January 28, 1910). [16] This is not marked in this map. According to the evolution of the two place names, this edition can be determined to be printed in late Guangxu Period of the Qing Dynasty (1903-1908).

\section{Edition Identification Through Background Investigation}

Through the toponymic evolution and the taboo clue, the edition analysis points could be carefully and sensitively grasped, which is a point-based in-depth textual research method. Moreover, the points could be extended to areas, that is to investigate relevant background about the map, such as the map compilation history, the thematic maps' background, and the divergent associated background investigation. Due to the complexity of map types and the richness of information contained in maps, researchers shall accumulate more rich knowledge and adopt diversified research methods in the edition identification.

\subsection{Background Investigation Associated with Map Compilation History}

Unified Annals was revised for three times during the above 150 years from the Kangxi Period, the Yongzheng Period, the Qianlong Period, the Jiaqing Period and the Daoguang Period of the Qing Dynasty into three great works, namely Unified Annals of the Qing Dynasty of the Kangxi
Period, Unified Imperial Annals of the Qing Dynasty of the Qianlong Period and Revised Unified Annals of the Qing Dynasty of the Jiaqing Period. [17] The compilation of Unified Annals directly drove the compilation local annals, and the latter naturally contained local maps. Comprehensive Atlas of Linan Prefecture of Yunnan (NC/3078.5/4447) is a color-drawing folded brochure, containing 10-view maps and minority maps. In the illustration part, the words of "Reconstruction of City God in the $22^{\text {nd }}$ Year of the Kangxi Period" were found. This information shows that the atlas is a part of Unified Annals of the Qing Dynasty which compiled in the $24^{\text {th }}$ year of the Kangxi Period. During the period, all of the provinces were ordered to draw maps of fortresses, mountains, rivers, city wall and moat, roads, and local conditions and customs, and the "Map of Linan Prefecture" was drawn by $\mathrm{Li}$ Hui. Therefore, the edition year is determined to be in the Kangxi Period of the Qing Dynasty (1685-1687).

Maps of States and Counties of Zhaoqing Prefecture (NC/3078.2/3007) is another color-drawing collection. On the map, there are some words described that two gate towers were built in the $7^{\text {th }}$ year of the Shunzhi Period, and city walls were built in the $4^{\text {th }}$ year of the Kangxi Period. More particularly, all maps have only drawings, without any text notes. Due to the blanks in the maps, it can be inferred that is a painting draft drawn by Zhaoqing Prefecture of Guangzhou Province in the $24^{\text {th }}$ year of the Kangxi Period (1685) when all provinces presented the local maps for compiling Unified Annals of the Qing Dynasty.

Imperial Statutes of the Qing Dynasty is an important historical record of laws and regulations of the Qing Dynasty. It consists of three parts, namely literatures, examples and illustrations. Specifically, Illustrations of Ceremonies of the Qing Dynasty vividly depict altars, temples, imperial carriages, honor guards, armaments, astronomy and land. The Qing Government compiled the Statutes for the fifth time in the $12^{\text {th }}$ year of the Guangxu Period (1886), and ordered all provinces to redraw local maps in the $15^{\text {th }}$ year. Kupu Sugulezhuoer Wulianghai Map (SB/981.25/0846) is a product of this historical period. As a color-ink map, it is also attached with additional descriptions, which says that Kupu Sugulezhuoer Wulianghai Governor Qishike Jiergele draws the map of affiliated prairie in accordance with the imperial example of provincial map that requires dividing into grids (50km for each) regardless of the number of grids and the size. According to the records, it can be inferred that the map of affiliated prairie was drawn when the department of statutes presided over the drawing of local maps in the $16^{\text {th }}$ year of the Guangxu Period (1890).

Apparently, the edition identification of such maps is associated with the background of the historical document compilation of the Qing Dynasty. Therefore, in the collation work of ancient Chinese maps, it is necessary to master certain historical knowledge, understand the compilation history of ancient Chinese maps, and some important events during the compilation of maps, so as to sensitively identify the products of various maps in a specific historical period, 
understand the drawing purpose and drawing methods, and accurately judge the edition year and the edition value.

\subsection{Background Investigation Associated with Thematic Maps}

Ancient Chinese maps also include various types of thematic maps, and each theme involves relevant background, such as geology, water conservancy, post and telecommunications, and transportation. During the collation of such maps, efforts shall be made to further investigate its thematic background.

Map of Six Major Rivers around Capital (X/981.348/2504) is a block-printed ink map attached with descriptions for the use of reviewing the origin and development of the six major rivers, namely Ziya River, Yongding River, South Canal, North Canal, Qinghe River and Luanhe River. The identification of the printing year of this map is associated with the analysis of the background of the "rechanneling of Yellow River". After the Daoguang Period of the Qing Dynasty, flood of Yellow River had become more and more serious. The increasing batture of downstream river channel of Yellow River caused constant crevasse, overflow and rechanneling below the intersection between Yellow River and Beijing-Hangzhou Grand Canal, which led to the overall accretion of terrains in the downstream coastal area of Yellow River. In the $5^{\text {th }}$ year of the Xianfeng Period of the Qing Dynasty (1855), due to the long-term sedimentation, Yellow River burst in Tongwaxiang, Lanyang County, Kaifeng, and flew northward through states and counties of Henan Province and Shandong Province and cross Beijing-Hangzhou Grand Canal in Zhangqiu Town, Shandong Province, occupied Daqing River and flew into Bohai Sea in Lijin County, so as to change Yellow River's discharge into sea through Huaihe River in South China for hundreds of years.[18] This map exactly reflects the situations behind the re-channeling background of Yellow River. Because the Yellow River flew northward, damaged the canal, changed the river system and impact rivers around capital, this map was drawn to depict the new river system around capital and their source and end. The printing year of this map is after the $5^{\text {th }}$ year of the Xianfeng Period in late Qing Dynasty (1856-1909).

Comprehensive Map of Yangtze River at North and South Banks through Jiangsu, Jiangxi, Hunan, Hubei and Anhui Provinces (NC/3078/3431) is a color-ink folded brochure that depicts Yangtze River flowing from Tongzhou, Jiangsu Province, westward to Jingzhou, Hubei Province through Jiangsu, Jiangxi, Hunan, Hubei and Anhui Provinces in details. The edition year of this map shall be identified under the historical background of Yangtze River navy of the Qing Dynasty. Until Xianfeng Period, the Qing government had not established any military unit with a unified organizational system and a throughout command system on Yangtze River, and patrol, anti-smuggling and other tasks were still governed separately by green camps of provinces along Yangtze River. After Taiping Revolution, Yangtze River basin became a war zone between Taiping
Army and Qing Army...In the $2^{\text {nd }}$ month of the first year of the Tongzhi Period (1861), after Hunan Army attacked and occupied Anqing, Zeng Guofan submitted a memorial and requested to establish Yangtze River navy. [19] It was finally approved by the Qing Government. In the $3^{\text {rd }}$ and $4^{\text {th }}$ years of the Tongzhi Period, Zeng Guofan and governors of provinces along Yangtze River discussed and formulated the matters and camp system associated with Yangtze River Navy. This map is marked with such characters as "Anqing Deputy General Camp", "Jinling Staff General Camp" and "Bahe Guerrilla Camp", which are all under the organizational system of Yangtze River Navy determined by Zeng Guofan in the $12^{\text {th }}$ month of the $4^{\text {th }}$ year of the Tongzhi Period (1865). Therefore, this map was drawn in the Tongzhi Period (1865-1874).

\subsection{Divergent Associated Background Investigation}

The above two background investigation methods are directly associated with the content expressed in ancient Chinese maps. In addition, information contained in a map may also have a "divergent" associated background. In this case, the edition year could be inferred through implied clues. For instance, Comprehensive Map of North Canal (X/981.27349/1338) is an ink-drawing paper map with slight defects. The map depicts all of towns and villages through the whole process of North Canal starting in Shunyi through Tongxian County and Xianghe to Tianjin. It is also pasted with two white paper floating labels to record the information of water level rise. Besides, this map is also characterized by the marks of "railway", such as the mark of railway drawn beside "Tongxian County". Tongxian County Branch Line is originally named Tongzhou Branch Line, and located in the east of Beijing. From the slip switch at $2.214 \mathrm{~km}$ from Dongbianmen Station of Beijing-Shandong Railway, the line runs eastward via the city moat, then southward along Tonghui River, and past Shuangqiao and Baotongsi to the west bank at the southeast corner out of Tongzhou City that is a portal to capital and an important water transport town, with a total length of $21.945 \mathrm{~km}$... The construction of the line started in 1901 and completed in the year. [20] According to the time of railway construction, it is estimated that the map was drawn from the Guangxu Period to the Xuantong Period of the Qing Dynasty (1902-1910).

Likewise, Blank Map of Qing Empire (X/981.2/4306) is a color-ink edition of the Commercial Press, but with a lack of publication year. The "blank map" is used for teaching and marked by symbols without any word. In addition to symbols of prefecture, county, state, boundary and river in the map, there are also two different types of symbols, namely "railway under construction" and "completed railway". It is the latter two that could provide the basis for identifying the printing year. On this map, "Beijing-Hankou Railway" located in the middle of Hebei Province, Henan Province and Hubei Province was marked as a "completed railway", while "Zhengding-Taiyuan Railway" between Shijiazhuang and Taiyuan is marked as a "railway under construction". The construction of Beijing-Hankou Railway started at both ends 
at the end of 1898, and Yellow River Railway Bridge was completed on November 15, 1905. On April 1 of the next year, the whole line was completed and opened to traffic.[21] Zhengding-Taiyuan Railway is currently known as Shijiazhuang-Taiyuan Railway, and was named so because of its starting point at former Zhengding, Hebei Province. Its construction started in 1904. This Railway was completed and open to traffic in the $10^{\text {th }}$ month of the $33^{\text {rd }}$ year of the Guangxu Period (1907). [22] Based on the analysis of the completion time points of the two railways, it is inferred that the printing year of the map is the $32^{\text {nd }}$ year of the Guangxu Period of the Qing Dynasty (1906).

As mentioned above, no matter maps of rivers and towns or comprehensive geographical maps of China, the railway engineering construction background investigation plays a critical role for edition identification. That is to say, the textual research for the edition year of maps shall be made from the comprehensive perspective, in order to find valuable information in graph, and extend the divergent associated background investigation. This is likely to bring unexpected benefits.

\section{Edition Identification Based on Archives}

Professor Li Xiaocong once wrote, ancient Chinese maps shall be taken as the supplements of textual historical materials; and their content shall be regarded as the products of systems, figures and events of a specific historical stage in the space. Therefore, in the research for ancient Chinese maps, textual historical materials shall also be emphasized. Specifically, the research shall be conducted based on the archives of the Qing Dynasty, in addition to ancient Chinese maps alone. [23] During the collation work of ancient Chinese maps, although a specialized research is not required for the content of ancient Chinese maps, relevant important archives could also play a key role in the identification of edition year.

Topographic Map of Border of Surname Ka in East of Mayan River (SB/981.243/6456) is a color edition that depicts terrains between the east of Mayan River (also known as Mayi River), Huerha River (today's Muda River) and the northern bank of Songhua River. In the lower left corner is Sanxing Town (established in the third year of Kangxi Period, today's Yilan). According to Volume 97 of Memoir of Emperor Dezongjing of the Qing Dynasty, in late June of the $5^{\text {th }}$ year of the Guangxu Period, General Jilin Ming An et al submitted a memorial to report the investigation for wastelands at both banks of Mayan River affiliated to Alechuka; according to the report, Pangtoupao was connected to Gongshan Mountain and had not been reclaimed. [24] This historical record is found to be correlated with the content in the map. Therefore, the edition year of this map is identified to be the $5^{\text {th }}$ year of the Guangxu Period of the Qing Dynasty (1879).

During the textual research for the edition year of Map of
Boundary of Phoenix Town (SB/981.241/7737), another important historical archive is been discovered. According to Volume 456 of Memoir of Emperor Xuanzongcheng of the Qing Dynasty, in the $6^{\text {th }}$ month of the $28^{\text {th }}$ year of the Daoguang Period, the cabinet was ordered to review Map of Boundary of Phoenix Town, and draft a memorial about the situations. Because the original mileage set forth in the map was inaccurate and confused, the generals personally investigated the terrains of the four mountains and the actual areas of arable lands, wastelands and meadows. The boundary mark was established along approximate straight lines below the western slope of Guangtu Mountain. All of the generals must fulfill the mission according to resolution of the congress. [25] These sentences clearly record the objective and purpose for drawing Map of Boundary of Phoenix Town and the background of presenting it to the court. Therefore, this map is identified as a color-drawing edition in the $28^{\text {th }}$ year of the Daoguang Period of the Qing Dynasty (1848).

It can be seen that ancient Chinese maps are likely to be correlated with government decrees of various historical periods, and were drawn and presented under a specific government decree in a specific period. If ancient Chinese map collation workers boast a broad vision of literature, and accurately find relevant archives and materials with historical research methods, they can better understand the background of ancient Chinese maps and naturally solve some difficulties.

\section{Conclusion}

Based on a large number of examples for identifying ancient Chinese maps as mentioned above, four textual research methods for identifying editions of ancient Chinese maps are summarized in this paper. Of course, in actual collation work, comprehensive clues shall be applied in an overall analysis and research for editions of ancient Chinese maps. As an old Chinese saying goes, "One should be well informed of both ancient and modern books before distinguishing the genuine and counterfeit." This indicates that the textual research for editions requires abundant experience of identification and profound ancient and modern knowledge. Regarding the textual research for editions of ancient Chinese books, edition experts offer many constructive methods. However, the textual research on maps highlights its own peculiarity while sharing some same features as that of ancient Chinese books. This work requires accumulated practical experience during the actual work, as well as constant learning to increase comprehensive knowledge. In particular, different thematic maps involve various disciplines, which requires that collators and researchers shall have more extensive disciplinary knowledge.

Ancient Chinese maps are so valuable that they cannot be replaced by historical text materials. Particularly, now is a "map-reading age" in the $21^{\text {st }}$ century, images and videos have gradually become the main information sources for 
humans. Accordingly, ancient maps have gained increasing attention from researchers, with a higher academic value and practical significance. Therefore, libraries shall further improve the collation of ancient Chinese maps, and comprehensively study them so as to advance various researches. The project of publishing ancient Chinese maps in Peking University Library will be a good effort. Until today, all the maps have been scanned, and it is expected to be officially published at the end of this year.

\section{References}

[1] Li Xiaocong. Enlightenment of Ancient Chinese Maps [J]. Reading, 1997 (7): 142.

[2] Li Xiaocong. Enlightenment of Ancient Chinese Maps [J]. Reading, 1997 (7):143.

[3] Chen Yuan. Examples of Historical Taboos [M]. Beijing: Zhonghua Book Company, 1962: Preface 1.

[4] Li Zhizhong. Overview of Textology of Ancient Books [M]. Beijing: Beijing Library Press, 1990 (reprinted in 2003): 162.

[5] Li Zhizhong. Overview of Textology of Ancient Books [M]. Beijing: Beijing Library Press, 1990 (reprinted in 2003):162-166.

[6] Niu Pinghan. Comprehensive Table of Evolution of Administrative Districts of the Qing Dynasty [M]. Beijing: Sinomaps Press, 1990: stylistic rules and layout 1.

[7] Niu Pinghan. Comprehensive Table of Evolution of Administrative Districts of the Qing Dynasty [M]. Beijing: Sinomaps Press, 1990:4.

[8] Niu Pinghan. Comprehensive Table of Evolution of Administrative Districts of the Qing Dynasty [M]. Beijing: Sinomaps Press, 1990:184.

[9] Niu Pinghan. Comprehensive Table of Evolution of Administrative Districts of the Qing Dynasty [M]. Beijing: Sinomaps Press, 1990:177.

[10] Niu Pinghan. Comprehensive Table of Evolution of Administrative Districts of the Qing Dynasty [M]. Beijing: Sinomaps Press, 1990:437.

[11] Chen Yuan. Examples of Historical Taboos [M]. Beijing: Zhonghua Book Company, 1962:170.
[12] Niu Pinghan. Comprehensive Table of Evolution of Administrative Districts of the Qing Dynasty [M]. Beijing: Sinomaps Press, 1990:79.

[13] Niu Pinghan. Comprehensive Table of Evolution of Administrative Districts of the Qing Dynasty [M]. Beijing: Sinomaps Press, 1990:80.

[14] Niu Pinghan. Comprehensive Table of Evolution of Administrative Districts of the Qing Dynasty [M]. Beijing: Sinomaps Press, 1990:108.

[15] Niu Pinghan. Comprehensive Table of Evolution of Administrative Districts of the Qing Dynasty [M]. Beijing: Sinomaps Press, 1990:314.

[16] Niu Pinghan. Comprehensive Table of Evolution of Administrative Districts of the Qing Dynasty [M]. Beijing: Sinomaps Press, 1990:8.

[17] Niu Runzhen, Zhang Hui. Textual Research on compilation of Unified Annals of the Qing Dynasty [J]. Research on the history of Qing Dynasty, 2008 (1): 136.

[18] Xi Huidong. Yellow River Rechanneling and River Policy Reform in Late Qing Dynasty--Centered on Drawing and Utilization of "Yellow River Rechanneling Map" [J]. Essays of Chinese History and Geography, 2013 (3):142.

[19] Tian Yuhong, Ji Zhenqi. Review of Yangtze River Navy in Late Qing Dynasty [J]. History teaching problems, 2009 (6):48.

[20] Zhang Yucai. Brief History of China's Railway Construction: 1876-1949 [M]. Beijing: China Railway Press, 1997:15.

[21] Zhang Yucai. Brief History of China's Railway Construction: 1876-1949 [M]. Beijing: China Railway Press, 1997:27.

[22] Ma Qianli, Lu Yizhi, Wang Kaiji. Brief History of Chinese Railway Architecture (1881-1981) [M]. Proofread by Wang Xuejun. Beijing: China Railway Press, 1983: 21.

[23] Li Xiaocong. Map of River Transport Work in Huang-Huai Area and Its Scientific Value [J]. Journal of Hydraulic Engineering, 2008 (8): 953.

[24] Memoir of Emperor Dezongjing (II), Book 53 of Memoir of the Qing Dynasty $[\mathrm{M}]$. Beijing: Zhonghua Book Company, 1987: 451 .

[25] Memoir of Emperor Xuanzongcheng (VII), Book 39 of Memoir of the Qing Dynasty [M]. Beijing: Zhonghua Book Company, 1987: 759. 